\title{
Inactivation of Chikungunya virus by 1,5 iodonapthyl azide
}

Anuj Sharma ${ }^{1}$, Paridhi Gupta ${ }^{1,2}$ and Radha K Maheshwari ${ }^{*}$

\begin{abstract}
Background: Chikungunya virus (CHIKV) is an arthropod borne alphavirus of the family Togaviridae. CHIKV is a reemerging virus for which there is no safe prophylactic vaccine. A live attenuated strain of CHIKV, CHIK181/25, was previously demonstrated to be highly immunogenic in humans, however, it showed residual virulence causing transient arthralgia.
\end{abstract}

Findings: In this study, we demonstrate the complete inactivation of CHIKV181/25 by 1,5 iodonapthyl azide (INA). No cytopathic effect and virus replication was observed in cells infected with the INA-inactivated CHIKV. However, a reduction in the INA-inactivated CHIK virus-antibody binding capacity was observed by western blot analysis.

Conclusion: INA completely inactivated CHIKV and can further be explored for developing an inactivated-CHIKV vaccine.

Keywords: Chikungunya virus, Inactivated vaccine, lodonapthyl azide

\section{Findings}

Earlier we have shown that 1,5 iodonapthyl azide (INA) and UV irradiation completely inactivated the Venezuelan equine encephalitis virus (VEEV) [1,2]. In this study, we have extended that approach to evaluate the inactivation of Chikungunya virus (CHIKV). CHIKV is an arthropod borne alphavirus of the family Togaviridae. It is a reemerging virus that has caused wide spread outbreak in the nations surrounding the Indian Ocean and Africa since 2004 [3]. Among the alphaviruses, CHIKV is one of the most important human pathogens due to the frequent outbreaks worldwide, causing large scale morbidity and economic losses. CHIKV infection has been reported in the travelers returning from the epidemic regions, thereby indicating a potential of dissemination to the previously known naïve regions for CHIKV [4]. Further, E1-A226V mutation in the CHIKV strain of 2005-2006 outbreak has increased the susceptibility of Aedes albopictus, which is endemic to the previously CHIKV naïve regions [5,6]. Therefore, there is an ever increasing risk of CHIKV outbreak in the areas such as the United States of America, where CHIKV is not

\footnotetext{
* Correspondence: radha.maheshwari@usuhs.edu

'Department of Pathology, Uniformed Services University of the Health

Sciences, 4301 Jones Bridge Road, Bethesda, MD 20814, USA

Full list of author information is available at the end of the article
}

endemic. Such potential outbreak may be devastating due to lack of immunity to CHIKV in the endemic population. There are no specific drugs against CHIKV and patients are symptomatically treated with non steroid anti-inflammatory drugs [7]. In the absence of antiviral drugs, preventive measures that include effective CHIKV vaccine are urgently needed. The United States Army had developed and tested a live attenuated strain of CHIKV, CHIKV181/25 for vaccine application. CHIKV181/25 demonstrated an excellent immunogenic profile (98\% seroconversion), however, transient arthralgia was observed in about $8 \%$ of vaccine recipients [8]. Several other approaches such as chimeric CHIKV on other alphavirus backbone, CHIK virus like particles, formalin inactivated CHIKV, DNA immunization and passive immunization with human polyvalent immunoglobulin have also been tested [9-13].

INA is a photoactive hydrophobic azide molecule that sequesters in the hydrophobic domain of the biomembranes and binds to the membrane proteins upon irradiation with long wavelength ultra-violet (UV) light. It was initially used for labeling the biological membranes [14]. Interaction of INA with proteins inactivates the membrane protein while conserving the ectodomain protruding outside the membrane [15]. This property of INA has been used to inactivate influenza virus, Ebola virus, 
VEEV, vaccinia virus, pixuna virus, simian and human immunodeficiency viruses and provide potential vaccine candidates $[1,2,15-18]$. In this study, we have evaluated the dose dependent inactivation of CHIKV181/25 by INA.

CHIKV181/25 was kindly provided by Drs. Parker MD and Glass PJ of the United States Army Medical Research Institute (USAMRIID), Frederick, MD. INA was obtained from Dr. Blumenthal RM, NCI, Frederick under a material transfer agreement. $0.5 \mathrm{mg}$ of sucrose gradient purified CHIKV was diluted with $1 \mathrm{X}$ DPBS and vortexed to mix and disintegrate the virus clusters. $20 \mathrm{mM}$ INA was then added to make a final concentration of INA to 50, 100 and $200 \mu \mathrm{M}$. The final volume of the reaction was set at $1.0 \mathrm{ml}$. Virus + INA suspension was then irradiated with UV radiation for a total of $5 \mathrm{~min}$ as described before [1,2]. Samples were irradiated with long wavelength UV radiation. A glass filter was used to filter out the short wavelength UV radiation [1]. Samples were then immediately stored at $-80^{\circ} \mathrm{C}$ until further use. Preliminary screening of virus inactivation was done by infecting BHK cells with a multiplicity of infection (MOI) of 1 . Cells were observed for virus induced cytopathic effect (CPE) such as rounding and sloughing off from the surface and were stained with $0.1 \%$ crystal violet solution in $4 \%$ neutral buffered formalin. In our previous study, we have used glutathione to quench the free INA that may be present in the virus suspension [1]. However, in this study, addition of glutathione alone to the virus suspension resulted in an inconsistent non-specific inhibition of CHIKV181/25 infectivity (data not shown). Therefore, glutathione was omitted in the final inactivation experiments in the present study. Replication of INA-inactivated CHIKV in BHK cells was also evaluated by CHIKV specific immunofluorescence. Briefly, cells were infected with MOI of 1 and at $48 \mathrm{hr}$ post infection fixed with 1:1 acetone: methanol for $10 \mathrm{~min}$ at room temperature. Slides were blocked with 1\% BSA for $45 \mathrm{~min}$ at room temperature followed by incubation with primary antibody (1:200, CHIKV hyper-immune mouse ascetic sera, Cata$\log \#$ VR64, ATCC, Manassas, VA) for $1 \mathrm{hr}$ at $37^{\circ} \mathrm{C}$. Slides were then washed and secondary antibody (Rhodamine labeled goat anti-mouse IgG) was added and incubated for $30 \mathrm{~min}$ at $37^{\circ} \mathrm{C}$. Slides were washed and mounted using mounting media containing DAPI (Vectastain, Vector Labs Inc). Virus titer in the cell supernatants was measured by the standard plaque assay. Viral transcripts in the supernatant from the infected BHK cells were analyzed by real-time RT-PCR. The primer set used for the PCR was following; forward primer: 5-GCCAGACACGGAGACGCCAAC-3 and reverse primer: 5-TGACCCTACTGAGAACAGCAC-3. The primer set was targeted against the non-structural protein 4 gene of CHIKV181/25 with expected amplicon size of $340 \mathrm{bp}$. Western blot analysis was done to test the antibody binding capacity of INA-inactivated CHIKV using a polyclonal antibody against CHIKV. Briefly, $12.5 \mu \mathrm{g}$ of protein for each sample was separated on 4-20\% novex tris-glycine gel (Invitrogen Inc., Carlsbad VA). Protein bands were transferred on nitrocellulose membrane (Amhersham Biosciences UK Limited) at $125 \mathrm{~mA}$ overnight at $4^{\circ} \mathrm{C}$. Viral proteins were detected by standard western blot procedure using polyclonal antibody (1:200) against CHIKV (CHIKV hyper-immune mouse ascitic sera, Catalog\#VR64, ATCC, Manassas, VA) and alkaline phosphatase conjugated secondary antibody (1:25000 in 1XTBST, goat anti-mouse IgG, Catalog\# AP124A, Chemicon International). Blot was developed using $10 \mathrm{ml}$ substrate for alkaline phosphatase (Catalog\# S3841, Promega Inc., Madison, WI) at room temperature for $15 \mathrm{~min}$. A complete inactivation of CHIKV by INA was achieved in virus samples that were treated with INA in combination with UV irradiation. This group will now be addressed as INA-inactivated CHIKV through the rest of manuscript. No CPE was observed in the cells infected with INA-inactivated CHIKV (Figure 1A). Immunofluorescence staining for CHIKV also showed no viral antigen in the cells infected with INA-inactivated CHIKV whereas cells infected with non-inactivated CHIKV were positively stained for CHIKV antigen (Figure 2). Uninfected cells served as negative controls for CHIKV staining and infection. Virus titration by standard plaque assay [2] showed complete absence of CHIKV in supernatants from the cells infected with INA-inactivated CHIKV whereas significant viral titers were measured in the supernatants of cells infected with non-inactivated CHIKV (Figure 1B). Further, no viral transcripts were detected in the supernatant of cells infected with the CHIKV that was inactivated with 50 , 100 and $200 \mu \mathrm{M}$ dose of INA (Figure 1C, detection cutoff at $\mathrm{Ct}=33$ ). Similar results were observed in three repetitive experiments. Next, we investigated, if treatment with INA has any adverse effect on the antigenicity of CHIKV by western blot analysis. The binding capacity of the virus to antibody appears to be reduced in INAinactivated CHIKV virus samples (Figure 1D).

Our findings are important as CHIKV causes an ongoing outbreak affecting millions of people around the globe. An effective CHIKV vaccine is urgently needed to control the spread of CHIKV. Live attenuated CHIKV181/ 25 was shown to have an excellent immunogenicity; however, the clinical trial was halted due to issues with residual virulence causing transient arthralgia in the vaccine recipients [7]. The INA-inactivated CHIKV181/ 25 formulation may address the issue of residual virulence that is associated with live attenuated CHIKV181/ 25. INA-inactivation resulted in a relatively less binding 


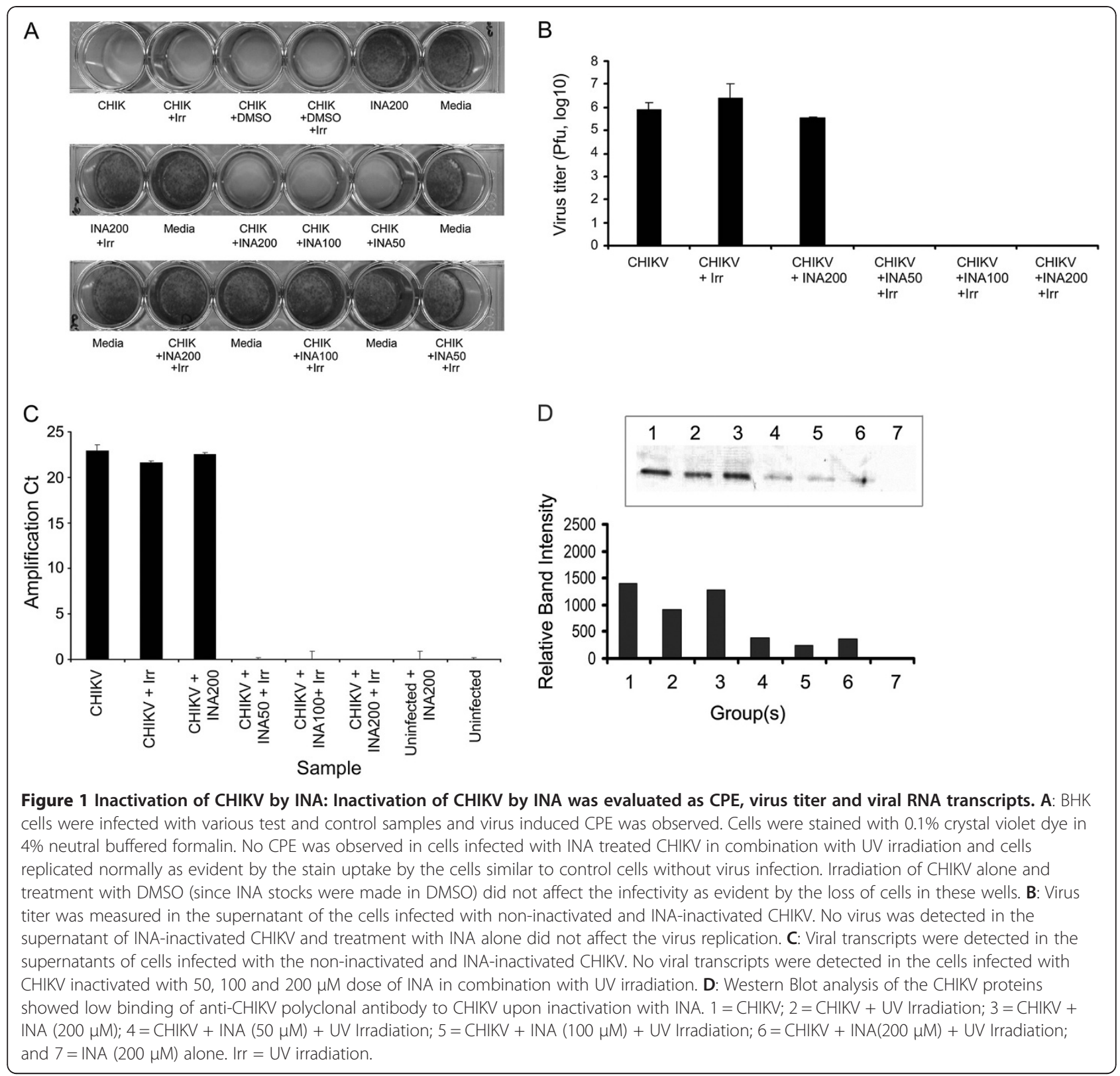

capacity of CHIKV181/25 to the neutralizing polyclonal anti-CHIKV E2 glycoprotein. This raises the question whether there may be some loss of antigenicity upon inactivation with INA. However, INA-inactivated CHIKV may still elicit a protective response against virulent CHIKV infection as shown with other INA-inactivated enveloped viruses such as VEEV, Ebola and Influenza virus. Chemical inactivation of CHIKV for vaccine purposes has been previously reported [11,19]. Formalin inactivated CHIKV was shown to induce neutralizing antibody and reduce homologous virulent virus titer [19]. Further testing of INA-inactivated CHIKV in the animal model will be needed for testing the protective efficacy of
INA-inactivated CHIKV181/25 as a vaccine candidate, and its advantage over current approaches of generating inactivated vaccines. To our knowledge this is the first study to show a complete inactivation of CHIKV181/25 using INA.

\section{Abbreviations}

CHIKV: Chikungunya virus; INA: 1, 5 iodonapthyl azide; BHK cells: Baby hamster kidney cells; CPE: Cytopathic effect; DAPI: 4',6-diamidino-2phenylindole; PBS: Phosphate buffered saline; BSA: Bovine serum albumin; RT-PCR: Reverse Transcription-Polymerase chain reaction.

\section{Competing interests}

The authors declare that they have no competing interests. 

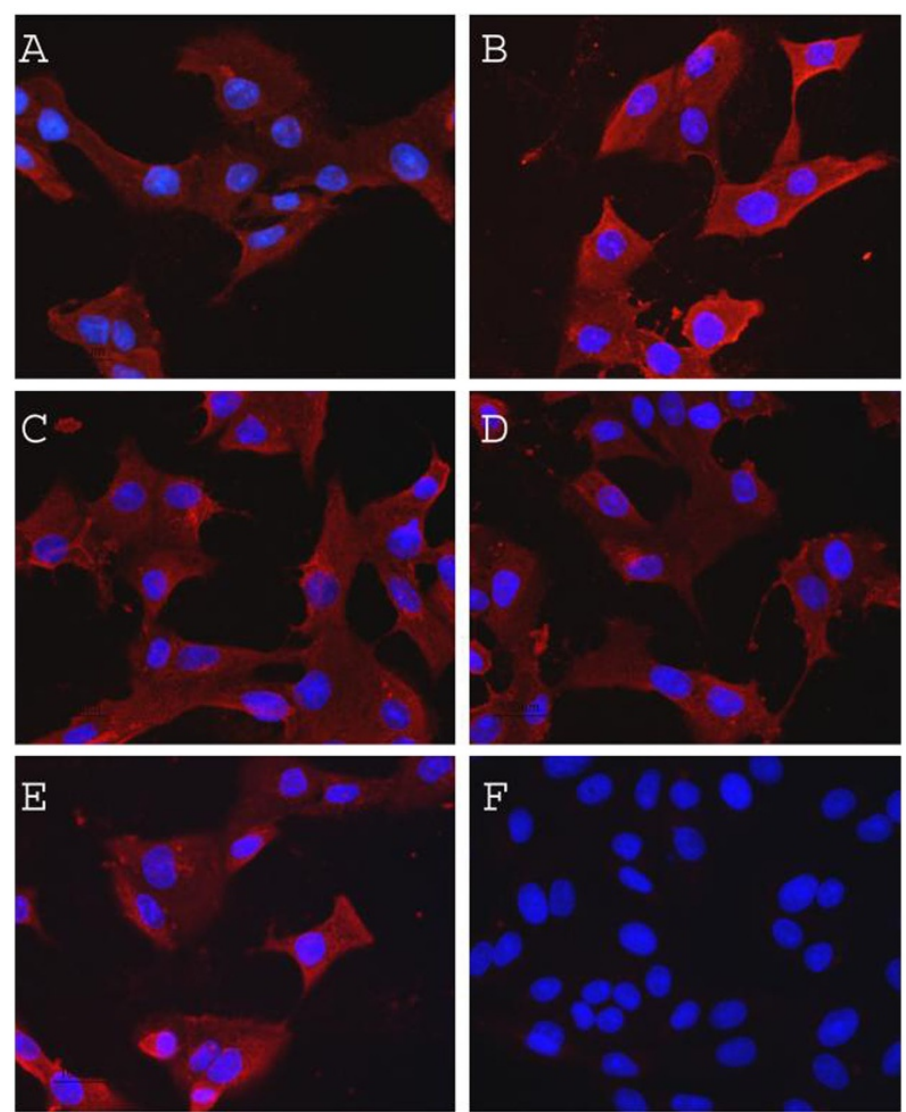

F
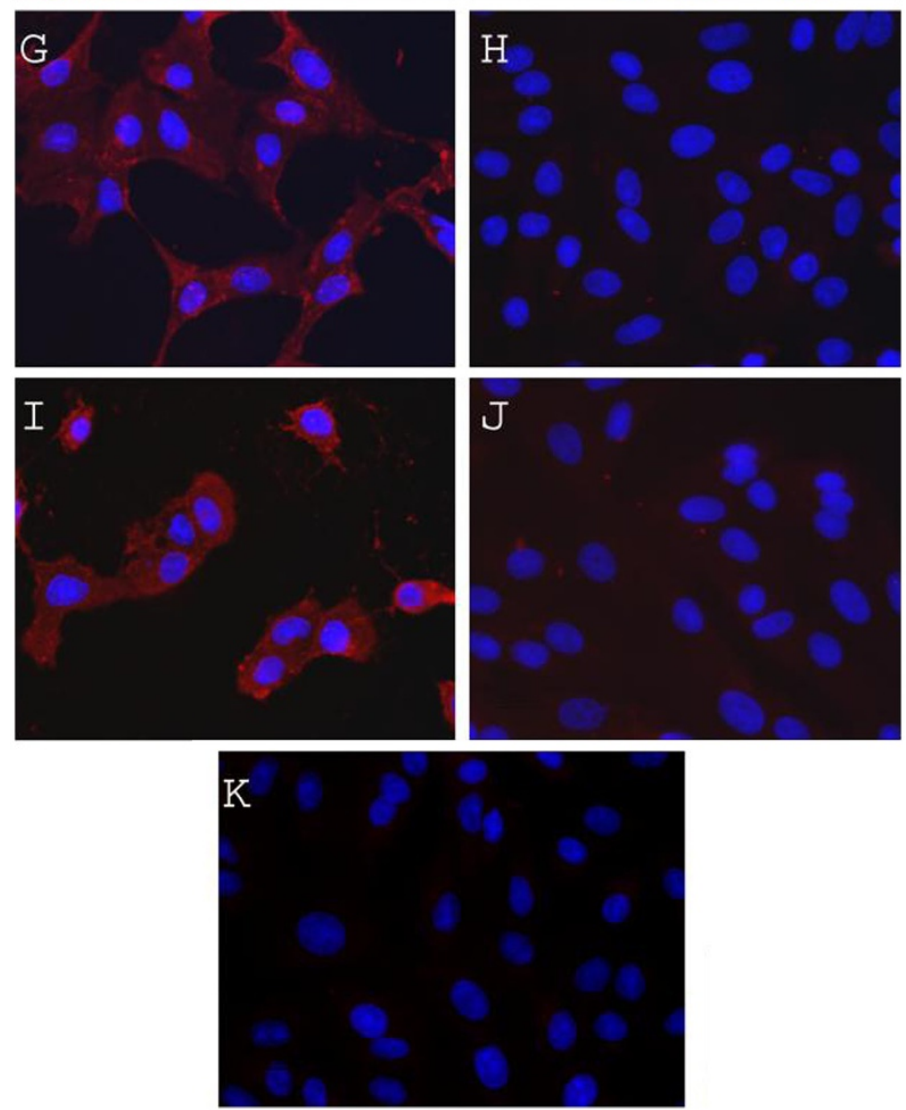

Figure 2 (See legend on next page.) 
(See figure on previous page.)

Figure 2 Evaluation of CHIKV inactivation by immunofluorescence: BHK cells were infected with non-inactivated and INA-inactivated CHIKV and CHIKV specific immunofluorescence was evaluated as described in the text. A: CHIKV; B: CHIKV + UV Irradiation; C: CHIKV +

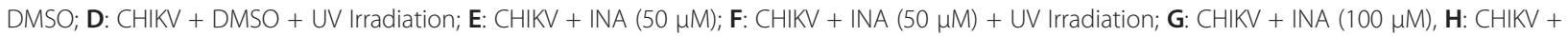

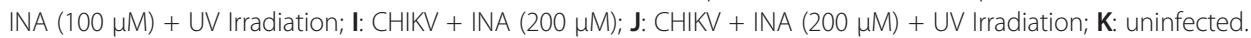

\section{Authors' contribution}

AS and RKM were involved in the conceptualization and designing of the study. AS carried out the inactivation experiment and analyzed the experimental data. PG carried out the western blot experiments. AS, RKM and PG participated in writing the manuscript. All authors read and approved the final manuscript.

\section{Acknowledgement}

These studies were supported by JSTO-CBD/DTRA Contract/Grant/ Intergovernmental Project Order/Project \# 4.10019_07_US_B and USAMRIID contract No. G174QH. Authors acknowledge the technical help from Mr. Gautham Sukumaran and Mr. Raghavendar Chandran. INA was provided by Dr. Robert Blumenthal, CCR Nanobiology Program, Centre for Cancer Research, National Cancer Research Institute, Frederick, MD under MTA. The opinions or assertions contained herein are the scientific views of the authors and should not be construed as official or necessarily reflecting the views or policies of the Uniformed Services University of the Health Sciences or the Department of Defense, USA.

\section{Author details}

'Department of Pathology, Uniformed Services University of the Health Sciences, 4301 Jones Bridge Road, Bethesda, MD 20814, USA. ${ }^{2}$ Department of Biological Sciences, Birla Institute of Technology and Science, Pilani, Rajasthan, India.

Received: 24 May 2012 Accepted: 15 November 2012

Published: 4 December 2012

\section{References}

1. Sharma A, Raviv Y, Puri A, Viard M, Blumenthal R, Maheshwari RK: Complete inactivation of Venezuelan equine encephalitis virus by 1,5iodonaphthylazide. Biochem Biophys Res Commun 2007, 358:392-398.

2. Sharma A, Gupta P, Glass PJ, Parker MD, Maheshwari RK: Safety and protective efficacy of INA-inactivated Venezuelan equine encephalitis virus: implication in vaccine development. Vaccine 2011, 29:953-959.

3. Das T, Jaffar-Bandjee MC, Hoarau JJ, Krejbich Trotot P, Denizot M, LeePat-Yuen G, Sahoo R, Guiraud P, Ramful D, Robin S, Alessandri JL, Gauzere BA, Gasque P: Chikungunya fever: CNS infection and pathologies of a re-emerging arbovirus. Prog Neurobiol 2010, 91:121-129.

4. Chen LH, Wilson ME: Dengue and chikungunya infections in travelers. Curr Opin Infect Dis 2010, 23:438-444.

5. Tsetsarkin KA, Vanlandingham DL, McGee CE, Higgs S: A single mutation in chikungunya virus affects vector specificity and epidemic potential. PLoS Pathog 2007, 3:e201.

6. Martin E, Moutailler S, Madec Y, Failloux AB: Differential responses of the mosquito Aedes albopictus from the Indian Ocean region to two chikungunya isolates. BMC Ecol 2010, 10(8):. doi:10.1186/1472-6785-10-8.

7. Chhabra M, Mittal V, Bhattacharya D, Rana U, Lal S: Chikungunya fever: a re-emerging viral infection. Indian J Med Microbiol 2008, 26:5-12.

8. Edelman R, Tacket CO, Wasserman SS, Bodison SA, Perry JG, Mangiafico JA: Phase II safety and immunogenicity study of live chikungunya virus vaccine TSI-GSD-218. AmJTrop Med Hyg 2000, 62:681-685.

9. Wang E, Volkova E, Adams AP, Forrester N, Xiao SY, Frolov I, Weaver SC: Chimeric alphavirus vaccine candidates for chikungunya. Vaccine 2008, 26:5030-5039.

10. Akahata W, Yang ZY, Andersen H, Sun S, Holdaway HA, Kong WP, Lewis MG Higgs S, Rossmann MG, Rao S, Nabel GJ: A virus-like particle vaccine for epidemic Chikungunya virus protects nonhuman primates against infection. Nat Med 2010, 16:334-338.

11. Tiwari M, Parida M, Santhosh SR, Khan M, Dash PK, Rao PV: Assessment of immunogenic potential of Vero adapted formalin inactivated vaccine derived from novel ECSA genotype of Chikungunya virus. Vaccine 2009, 27:2513-2522

12. Muthumani K, Lankaraman KM, Laddy DJ, Sundaram SG, Chung CW, Sako E, Wu L, Khan A, Sardesai N, Kim JJ, Vijayachari P, Weiner DB: Immunogenicity of novel consensus-based DNA vaccines against Chikungunya virus. Vaccine 2008, 26:5128-5134.

13. Couderc T, Khandoudi N, Grandadam M, Visse C, Gangneux N, Bagot S, Prost JF, Lecuit M: Prophylaxis and therapy for Chikungunya virus infection. J Infect Dis 2009, 200:516-523.

14. Bercovici T, Gitler C: 5-[125I]lodonaphthyl azide, a reagent to determine the penetration of proteins into the lipid bilayer of biological membranes. Biochemistry 1978, 17:1484-1489.

15. Raviv Y, Viard M, Bess JW Jr, Chertova E, Blumenthal R: Inactivation of retroviruses with preservation of structural integrity by targeting the hydrophobic domain of the viral envelope. J Virol 2005, 79:12394-12400.

16. Warfield KL, Swenson DL, Olinger GG, Kalina WV, Viard M, Aitichou M, Chi X, Ibrahim S, Blumenthal R, Raviv Y, Bavari S, Aman MJ: Ebola virus inactivation with preservation of antigenic and structural integrity by a photoinducible alkylating agent. J Infect Dis 2007, 196(Suppl 2):S276-S283.

17. Raviv Y, Blumenthal R, Tompkins SM, Humberd J, Hogan RJ, Viard M: Hydrophobic inactivation of influenza viruses confers preservation of viral structure with enhanced immunogenicity. J Virol 2008, 82:4612-4619.

18. Sagripanti J, Marschall H, Voss L, Hülseweh B: Photochemical Inactivation of Alpha- and Poxviruses. Photochem Photobiol 2003, 87(6):1369-1378.

19. Kumar M, Arankalle VA: Evaluation of recombinant E2 protein-based and whole-virus inactivated candidate vaccines against chikungunya virus. Vaccine 2012, 30:6142-6149.

doi:10.1186/1743-422X-9-301

Cite this article as: Sharma et al: Inactivation of Chikungunya virus by 1,5 iodonapthyl azide. Virology Journal 2012 9:301.

\section{Submit your next manuscript to BioMed Central and take full advantage of:}

- Convenient online submission

- Thorough peer review

- No space constraints or color figure charges

- Immediate publication on acceptance

- Inclusion in PubMed, CAS, Scopus and Google Scholar

- Research which is freely available for redistribution 